\title{
Escoamento superficial de água em plantios florestais de eucalipto, Felixlândia-MG
}

\author{
Ana Paula Vilela Carvalho ${ }^{1}$ \\ Herly Carlos Teixeira Dias ${ }^{1}$ \\ Vanessa Pataro Maffia ${ }^{1}$ \\ Otavio Surian Gamba ${ }^{1}$ \\ José Carlos de Oliveira Júnior ${ }^{2}$ \\ Tiago Carvalho de Morais ${ }^{2}$ \\ Warley Reis Silveira ${ }^{2}$ \\ ${ }^{1}$ Universidade Federal de Viçosa - UFV \\ CEP: 36570-000 - Viçosa - MG, Brasil \\ ana.vilela@ufv.br; herly@ufv.br; \\ vpmaffia@yahoo.com.br; otaviosurian@hotmail.com
${ }^{2}$ Plantar S/A-Departamento de Pesquisa e Meio Ambiente
CEP: 35790-000 - Curvelo - MG, Brasil
jose-oliveira@plantar.com.br; tiago-morais@plantar.com.br; warley.silveira@plantar.com.br

\begin{abstract}
The quantity of forests planted mainly with exotic species has been growing to supply the market requirement internal and external. This happen especially because of the forest products demand. The species of eucalyptus gender have a fast growth in compare to native species. This fact cause a big water demand, although the efficiency in the use of the water is better. The objective of this study was to find out the effective rainfall and total runoff provided by the "Riacho Fundo" watershed located in Felixlândia-MG, into different types of clones in the area of the Plantar Reforestation Company. With this work, we aim to obtain the knowledge of the water dynamics at productive forest systems with different kinds of clones. Besides, this work intend to propose a better practical management of eucalyptus plantations to provide appropriate amount of water with quality for different ends.
\end{abstract}

Palavras-chave: florestas plantadas, hidrologia florestal, bacia hidrográfica.

\section{Introdução}

A quantidade de florestas plantadas principalmente com espécies exóticas tem crescido a cada dia a fim de suprir a necessidade do mercado consumidor no que diz respeito à demanda crescente por produtos florestais. $O$ fato de o eucalipto ser uma espécie florestal de crescimento rápido tem causado preocupação ambiental, uma vez que pode provocar redução da quantidade de água contida no solo. O uso da água pela planta é controlado por diversos fatores que devem ser conhecidos, sendo que esses fatores englobam desde questões como umidade do solo até processos ocorridos na atmosfera, tais como radiação solar e temperatura do ar, passando é claro pela fisiologia do vegetal (condutância estomática) (Oleriano e Dias, 2007).

Segundo Lima (1996) o eucalipto é uma árvore que possui um crescimento muito acelerado por isso sua demanda por água é maior, porém não diferindo muito de outras espécies florestais. No entanto sua eficiência no uso de água é melhor que a de muitas 
espécies florestais, pois a quantidade de madeira produzida por unidade de água evapotranspirada é considerada alta, ou seja, o acúmulo de biomassa promovido pelo eucalipto é mais rápido em relação a algumas nativas. $\mathrm{O}$ eucalipto se desenvolve de três a cinco vezes mais rápido do que algumas árvores nativas, além de se apresentar com um tronco bem mais retilíneo.

A presença da floresta protege a superfície do solo dos efeitos da radiação solar e do vento e aumenta a superfície ativa, reduzindo dessa forma, a evaporação direta pelo piso florestal. No caso das áreas florestadas, a evaporação da água do solo ocorre pelo processo da transpiração. A evaporação direta da água do solo causa um secamento intenso, embora seja um fenômeno superficial. O secamento dessa camada superficial depende da textura do solo e, com as condições climáticas adequadas, passa a agir como barreira artificial ao secamento das camadas mais profundas do perfil (Balbinot et al., 2008).

Numa bacia hidrográfica florestal cuja cobertura seja uma floresta plantada, a regularidade do dossel faz com que a interceptação das gotas de chuva seja praticamente uniforme. As bacias hidrográficas florestais se comparadas com as de pastagens ou outro tipo de vegetação não florestal possuem uma vazão hipoteticamente menor. Isto ocorre porque as plantas no seu desenvolvimento necessitam de muita quantidade de água, principalmente nos estágios iniciais. Por isto as bacias não florestais apresentam maior vazão se comparadas com a outra (Oleriano e Dias, 2007).

Os regimes de corte raso ao final do período de rotação são fatores que também podem resultar em perdas consideráveis de solo por erosão. As perdas de solo e de nutrientes prejudicam tanto a qualidade da água quanto a manutenção da produtividade; dessa forma, é muito importante o manejo adequado das plantações florestais (Balbinot et al., 2008).

Um manejo que leve em consideração as características hidrológicas das microbacias desempenha um importante papel na manutenção da sua produtividade, assim como na conservação do crescimento florestal (Ranzini e Lima, 2002).

Baseando-se nas médias de precipitação maiores em áreas florestadas do que em áreas abertas, acreditava-se que a floresta contribuía para o aumento da precipitação local por meio da reciclagem das chuvas pelo processo de evapotranspiração. Outro fato que por vezes era mistificado é o de que bacias florestadas produzem mais água do que bacias com outro tipo de cobertura vegetal, porém o que acontece realmente é que na bacia com total cobertura florestal há uma menor produção de água, mas o fluxo é mais estável e sustentável do que em outros casos (Balbinot et al., 2008).

$\mathrm{Na}$ medida em que o manejo do solo, nas diversas atividades humanas, elimina a cobertura vegetal, sua superfície fica mais exposta à ação do impacto das gotas de chuva e da enxurrada. Desta forma, tanto o impacto das gotas de chuva quanto à enxurrada contribuem para modificar as condições físicas da superfície do solo, alterando a rugosidade superficial, a porosidade e a taxa de infiltração de água. O efeito da cobertura do solo na redução da velocidade do escoamento superficial da água é explicado pela tortuosidade dos caminhos a serem percorridos pelo fluxo, imposta pelos resíduos, bem como pela barreira física proporcionada pelos resíduos vegetais, impedindo o livre escoamento da água, sendo que esta redução é tanto maior quanto maior for a quantidade de resíduos vegetais ou culturais na superfície (Albuquerque et al, 2002).

Um aspecto importante para o entendimento das relações entre as florestas plantadas e a água é a questão da escala do uso da terra. A busca do manejo florestal sustentável das florestas plantadas tem que considerar sua característica inerente de múltiplas dimensões e de múltiplas escalas. Esta estratégia incorpora a noção da microbacia hidrográfica, como unidade sistêmica da paisagem e como escala natural dos processos hidrológicos envolvidos no balanço hídrico, na qualidade da água, no regime de vazão e na saúde do ecossistema 
aquático. Também Possibilita uma visão mais abrangente das relações entre o uso da terra, seja para a produção florestal, a produção agrícola, a abertura de estradas, a urbanização, enfim, toda e qualquer alteração antropica da paisagem, e a conservação dos recursos hídricos. Assim a sociedade acabará percebendo que o eventual problema da diminuição da água e da deterioração de sua qualidade, ou a degradação hidrológica, não está apenas nas florestas plantadas, mas numa infinidade de outras ações antropicas e de práticas inadequadas de manejo (Lima, 2004).

O presente trabalho tem por objetivo geral avaliar a precipitação efetiva e escoamento superficial na Bacia Hidrográfica do Riacho Fundo, Felixlândia-MG em sistemas florestais com diferentes tipos de clones.

\section{Materiais e Métodos}

\subsection{Localização e Caracterização da Área}

A Bacia Hidrográfica do Riacho Fundo deságua na represa de Três Marias, Rio São Francisco. A área de drenagem da cabeceira está integralmente localizada em áreas da Empresa Plantar Reflorestamentos, no município de Felixlândia-MG. A bacia de cabeceira é tipicamente florestal.

A cidade de Felixlândia está localizada na região Centro Norte de Minas Gerais (Figura 1). A vegetação típica do município é marcada pelo bioma do cerrado e o clima da região é predominantemente seco. A temperatura média anual é $22,6^{\circ} \mathrm{C}$, com temperaturas mínimas e máximas de respectivamente $16,6^{\circ} \mathrm{C}$ e $30,2^{\circ} \mathrm{C}$. Apresenta altitudes máximas e mínimas de 961 m e 502 m respectivamente. O índice médio pluviomêtrico anual na região do município é $1118,9 \mathrm{~mm}$.

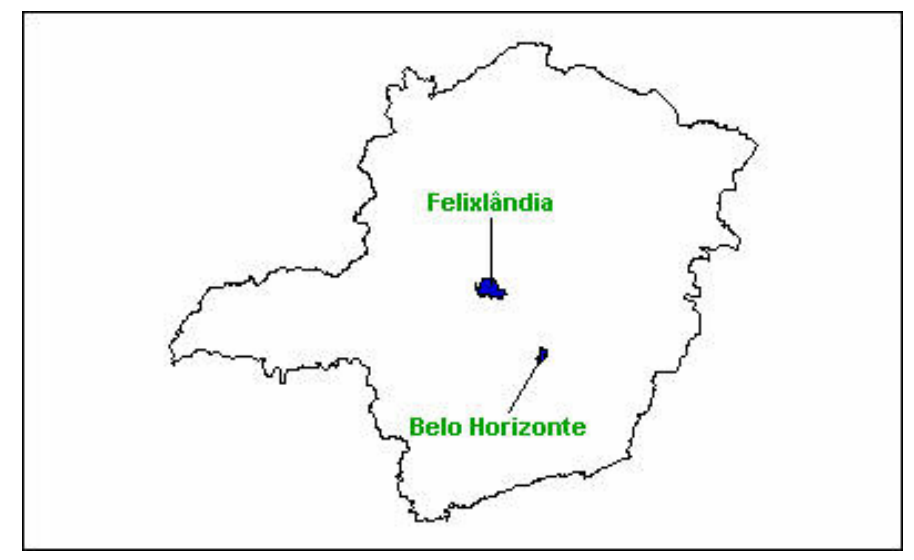

Figura 1: Localização do Município de Felixlândia no Estado de Minas Gerais.

Fonte: IGA (Instituto de Geociência Aplicada) em 10/05/1999.

\subsection{Processos Hidrológicos}

\subsubsection{Precipitação efetiva (PE)}

A precipitação efetiva é calculada pela a soma da precipitação interna (PI) e do escoamento pelo tronco (Et), como mostra a equação 1:

$\mathrm{PE}=\mathrm{PI}+\mathrm{Et}$ 
sendo,

$\mathrm{PE}=$ Precipitação efetiva $(\mathrm{mm})$;

PI = Precipitação interna $(\mathrm{mm})$;

$\mathrm{Et}=$ Escoamento pelo tronco $(\mathrm{mm})$.

\subsubsection{Precipitação interna (PI)}

Para quantificar a precipitação interna foram colocados doze pluviômetros em cada talhão, seis entre as linhas de plantio e seis na linha de plantio espaçado 5,25 metros (m) por 2,60 m e com área de captação de 176,71 cm² (Figura 2).

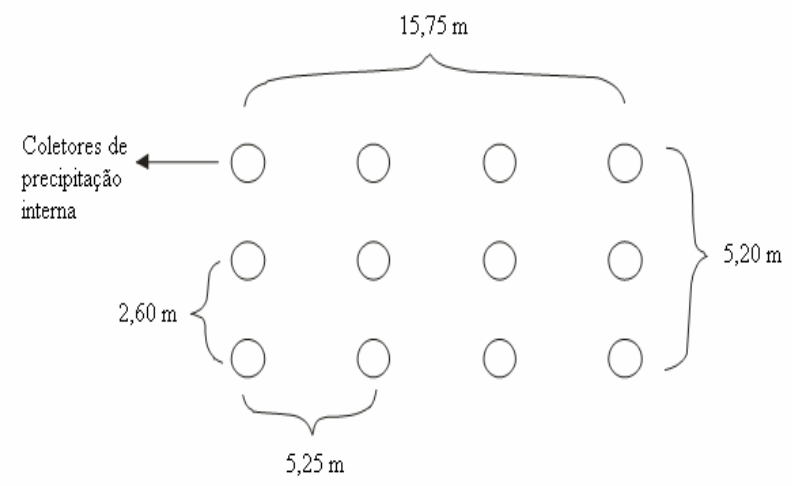

Figura 2: Esquema das parcelas para quantificar a precipitação interna nos talhões, bacia Córrego do Riachão, Felixlândia - MG, 2008.

\subsubsection{Escoamento pelo tronco (Et)}

Para quantificar o escoamento pelo tronco foram adaptados nove coletores à base de poliuretano nos troncos das árvores, sendo cinco em uma fileira e quatro em outra fileira adjacente.

\subsubsection{Escoamento superficial}

As parcelas experimentais localizadas na determinada área de estudo são delimitadas por placas de ardósia. Na parte inferior de cada parcela experimental, são colocados galões coletores acoplados por conexão tubular com declive suficiente para permitir o livre escoamento da água da chuva até o local de inserção do galão coletor.

O coeficiente de escoamento superficial é obtido através da fórmula matemática:

$$
\mathrm{C}=\mathrm{ES} / \mathrm{PT}
$$

Onde:

$\mathrm{C}=$ coeficiente de escoamento superficial

$\mathrm{ES}=$ lamina de água escoada $(\mathrm{mm})$

$\mathrm{PT}=$ lamina de água precipitada $(\mathrm{mm})$ 


\section{Resultados e Discussão}

Os componentes da precipitação efetiva e escoamento superficial foram monitorados no período de outubro de 2007 a novembro de 2008.

Observa-se pela Tabela 1 que existe uma provável diferença entre as precipitações efetivas dos diferentes talhões. Estas diferenças podem ser devido a morfologia dos diferentes clones plantados em cada uma das parcelas.

Os valores do escoamento superficial de água demonstram a fração da água de chuva que atinge o solo e corre superficialmente, por gravidade, sobre o piso florestal. Ou seja, para uma mesma intensidade de chuva os solos, com os respectivos usos e manejo, podem apresentar diferentes índices de escoamento de água de chuva superficialmente em função da declividade ou do manejo sobre o solo.

Verifica-se pela Tabela 1 que os valores de escoamento superficial variam entre parcelas, talhões, provavelmente devido ao conjunto de características que cada talhão apresenta. Incluem-se nestas características o solo, com menor variação, a declividade do terreno, a cobertura florestal e de sub-bosque, a produção de serapilheira e a características de cada clone utilizado. Verifica-se que as parcela 5 apresentou menor valor de escoamento superficial acumulado e a parcela 3 o maior. No entanto, o que chama a atenção são os baixos valores escoamento em relação a precipitação efetiva ocorrida em cada mês. Em valores acumulado o escoamento médio para a bacia, para as parcelas que estão localizadas nos maiores declives dos talhões, é de 0,2\% da precipitação efetiva, ou seja, de apenas 2,6 mm.

Isto demonstra que em termos de aproveitamento da água de chuva para infiltração é quase que total nestes ambientes, na idade em que se encontram.

Tabela 1 - Escoamento superficial de água de chuva, em mm e percentual (\%) e precipitação efetiva (PE) média, em parcelas na bacia hidrográfica do Riacho Fundo, Felixlândia, MG, 2008.

\begin{tabular}{|c|c|c|c|c|c|c|c|c|c|}
\hline & \multicolumn{6}{|c|}{ Parcela } & \multicolumn{2}{|c|}{ Média } & PE \\
\hline Mês/ano & 2 & 3 & 4 & 5 & 7 & 8 & $\mathrm{~mm}$ & $\%$ & $\mathrm{~mm}$ \\
\hline Out/07 & 0,07 & 0,04 & 0,1 & 0,05 & 0,08 & 0,06 & 0,06 & 0,3 & 23,95 \\
\hline Nov/07 & 0,07 & 0,07 & 0,1 & 0,04 & 0,07 & 0,04 & 0,4 & 0,3 & 116,22 \\
\hline Dez/07 & 0,4 & 0,3 & 0,5 & 0,2 & 0,4 & 0,3 & 0,4 & 0,4 & 111,79 \\
\hline Jan/08 & 0,6 & 0,9 & 1,1 & 0,3 & 0,1 & 0,4 & 0,6 & 0,2 & 268,56 \\
\hline Fev/08 & 0,6 & 0,6 & 0,2 & 0,5 & 0,1 & 0,3 & 0,4 & 0,2 & 198,89 \\
\hline Mar/08 & 1,0 & 1,1 & - & 0,8 & 0,2 & 0,6 & 0,7 & 0,3 & 235,09 \\
\hline Abr/08 & 0,08 & 0,1 & - & 0,0 & 0,0 & 0,02 & 0,05 & 0,1 & 39,42 \\
\hline Mai/08 & 0,0 & 0,0 & - & 0,0 & 0,0 & 0,0 & 0,0 & 0 & 0,00 \\
\hline Jun/08 & 0,0 & 0,0 & - & 0,0 & 0,0 & 0,0 & 0,0 & 0 & 0,00 \\
\hline $\begin{array}{ll}\mathrm{Jul} / 08 \\
\end{array}$ & 0,0 & 0,0 & - & 0,0 & 0,0 & 0,0 & 0,0 & 0 & 0,00 \\
\hline Ago/08 & 0,0 & 0,0 & - & 0,0 & 0,0 & 0,0 & 0,0 & 0 & 0,00 \\
\hline Set/08 & - & 0,01 & - & - & 0,00 & - & 0,005 & 0,1 & 7,96 \\
\hline Out/08 & - & 0,00 & - & - & 0,00 & - & 0,00 & 0 & 0,00 \\
\hline Nov/08 & - & 0,1 & - & - & - & - & 0,1 & 0,2 & 63,8 \\
\hline Dez/08 & - & - & - & - & - & - & - & - & - \\
\hline Acumulado & 2,8 & 3,1 & 2,0 & 1,9 & 0,95 & 1,7 & 2,6 & 0,2 & 1065,68 \\
\hline
\end{tabular}




\section{Conclusão}

Pelos resultados observados verifica-se que existem diferenças na precipitação efetiva entre talhões devido a uma provável influencia da morfologia do clone plantado em cada talhão. Pode-se concluir também que o escoamento superficial de água de chuva é pequeno em relação à precipitação efetiva e apresenta pouca variação ao longo do ano.

\section{Agradecimento}

Os autores agradecem ao financiamento da pesquisa fornecido pela Plantar Reflorestamento e a Fundação de Apóio a Pesquisa do Estado de Minas Gerais, FAPEMIG, por financiar a participação no SERHIDRO.

\section{Referências}

Albuquerque et al. Manejo da cobertura do solo e de práticas conservacionistas nas perdas de solo e água em Sumé, PB. Revista Brasileira de Engenharia Agrícola e Ambiental, v.6, n.1, p. 136-141, 2002. Disponível em: <http://www.scielo.br/pdf/rbeaa/v6n1/v6n1a24.pdf>. Acesso em: 6 ago. 2009.

Balbinot et al. O papel da floresta no ciclo hidrológico em bacias hidrográficas. Ambiência - Revista do Setor de Ciências Agrárias e Ambientais,v.4, n.1, 2008. Disponível em:<http://www.unicentro.br/editora/revistas/ambiencia/v4n1/O\%20papel\%20da\%20floresta\%20no\%20cic lo9\%20hidrol\%C3\%B3gico\%20em\%20bacias\%20hidrogr\%C3\%A1ficas\%20p.131-149.pdf>. Acesso em: 5 ago. 2009.

Lima, W.P., 2004. O eucalipto seca o solo? Boletim Informativo da Sociedade Brasileira de Ciência do Solo, 29: 13- 17.

Lima, W.P.; ZAKIA, M.J.B. Monitoramento de bacias hidrográficas em áreas florestadas. In: Workshop sobre monitoramento ambiental em áreas florestadas, 1, PIRACICABA, 1996. Memória. Série Técnica IPEF, v.10, n. 29, p.11-21, 1996.

Oleriano, E. S.; Dias, H.C.T. A dinâmica da água em microbacias hidrográficas reflorestadas com eucalipto. In: Anais I Seminário de Recursos Hídricos da Bacia Hidrográfica do Paraíba do Sul: o Eucalipto e o Ciclo Hidrológico, Taubaté, Brasil, 07-09 novembro 2007, IPABHi, p. 215-222.

Ranzini, M.; Lima, W. P. Comportamento hidrológico, balanço de nutrientes e perdas de solo em duas microbacias reflorestadas com Eucalyptus, no Vale do Paraíba, SP. Scientia Forestalis, n. 61, p. 144-159, 2002. Disponível em: <http://www.ipef.br/publicacoes/scientia/nr61/cap13.pdf>. Acesso em 6 ago. 2009. 